\title{
Race and Gender Differences in Medical Student Perspectives on Social Determinants of Health Education: A Single-Institution Survey Study
}

\author{
Arman A Shahriar $\mathbb{D}^{\prime}$ \\ Kriti Prasad' \\ Katherine Casty' \\ Zarin I Rahman' \\ Michael Westerhaus ${ }^{2,3}$ \\ David J Satin'
}

'University of Minnesota Medical School, Minneapolis, MN, USA; ${ }^{2}$ University of Minnesota, Global Medicine, Minneapolis, MN, USA; ${ }^{3}$ Center for International Health, St. Paul, MN, USA
Correspondence: Arman A Shahriar University of Minnesota Medical School, 420 Delaware St SE, Minneapolis, MN, 55455, USA

$\mathrm{Tel}+1$ 952-270-7950

Emailshahr019@umn.edu
Purpose: The field of medicine is becoming increasingly aware of the role that social determinants of health (SDH) play in shaping health and health outcomes. Organized medicine - including prominent physician groups and accreditation bodies - has endorsed $\mathrm{SDH}$ education as an integral component of medical school curricula. This study sought to describe medical student perspectives on the current state of SDH in preclinical curricula.

Methods: The authors developed a 9-item survey to assess time being spent on SDH and attitudes toward the current level of SDH content in preclinical curricula. All medical students at both campuses of a large public medical school were invited to participate between December 2019 and February 2020.

Results: Of 1010 medical students invited to participate, 515 (51.0\%) responded. Of the 515 respondents, $480(93.2 \%)$ reported spending at least 40 hours per week on medical school, and of those, $405(84.4 \%)$ said they spend $0-2$ hours on SDH. The majority of all respondents $(62.1 \% ; 320 / 515)$ felt the current level of focus on SDH is "not enough", while only eleven students $(2.1 \% ; 11 / 515)$ felt it is "too much". In a multiple logistic model, Black students were over four times as likely as white students (aOR 4.19; 95\% CI $1.37-18.38$ ) to feel the current level of focus on SDH is "not enough". Likewise, women were 2.3-times (aOR 2.30; 95\% CI 1.52-3.49) as likely as men to feel the level of focus on $\mathrm{SDH}$ is "not enough".

Conclusion: In practice, medical students are spending considerably less time learning SDH than is advised by consensus of expert educators and administrators. Over sixty percent of medical students do not feel the current level of focus on SDH is sufficient. Further study is needed to determine why women and racial minority students are significantly more likely to feel this way.

Keywords: social determinants of health, race/ethnicity, medical education, undergraduate medical education, undergraduate medical curriculum, social medicine, medical school, preclinical curriculum

\section{Introduction}

Health, health outcomes, and opportunities for wellness are rooted in historical and contemporary social forces such as racism, patriarchy, capitalism, and imperialism. From these structural forces emerge modern-day disparities in educational attainment, income, wealth, employment, and a host of other factors collectively deemed social determinants of health $(\mathrm{SDH})$. For example, living in a historically redlined 
neighborhood has been shown to correlate with risk of preterm birth, and exposure to adverse childhood experiences correlate with risk of future cardiovascular, rheumatologic, and endocrine disease. ${ }^{1,2}$ Further, physicians are prominent and powerful participants in both reinforcing and rectifying these social forces through clinical practice. ${ }^{3}$

As outlined by the US Department of Health and Human Services and research consensus, ${ }^{4,5}$ a primary strategy for attaining health equity is addressing SDH. Knowing this, many experts, including the American College of Physicians, the Society for General Internal Medicine, and the Liaison Committee on Medical Education (LCME) believe that SDH education is an integral component of undergraduate medical curriculum, ${ }^{6,7}$ and mandate its inclusion. ${ }^{8,9}$ According to the American Association of Medical Colleges (AAMC), about two-thirds of medical schools have required SDH content in their pre-clinical curriculum as of 2019. ${ }^{10}$ However, beyond simply including SDH, there has been little guidance for educators on how to teach SDH, both with respect to curricular structure and time allocation. Although a recent panel of diverse experts in medical education achieved consensus that SDH ought to constitute $29 \%$ of total undergraduate medical curriculum, ${ }^{4}$ high-profile opponents like the former University of Pennsylvania Dean of Medical Education argue that undergraduate medical education is exceeding its scope by integrating SDH. ${ }^{11}$

Despite significant input from educators, administrators, and policymakers regarding SDH in undergraduate medical education, to our knowledge the perspective of medical students is missing in the literature. We hypothesized that most medical students feel that SDH deserve more focus in medical school curricula.

Certain students who hold marginalized gender and racial identities may disproportionately feel this way. In medical school specifically, women and BIPOC students are significantly more likely to report experiencing gender- or race-based discrimination than their male and white counterparts. ${ }^{12}$ Women's lived experiences are rooted in patriarchy and include sexism, sexual violence, unequal pay and unequal access to opportunity. Likewise, the lived experiences of BIPOC students include racial trauma as well as a myriad of consequences arising from systemic racism, including police brutality, wealth inequality, and discriminatory housing policy. ${ }^{13}$ We thus hypothesized that gender and racial minority students specifically students identifying as women and Black, Indigenous, and People of Color (BIPOC) - may desire more SDH content than their peers, as these students are more likely to experience negative impacts of social forces on themselves, their families, and their communities.

In this student-initiated and student-led study at two campuses of a large, public medical school (The University of Minnesota - Minneapolis and Duluth Campuses), we sought to investigate these gaps. Minnesota has a population of about 5.6 million, half of whom are female. Additionally, $84 \%$ self-identify as white, $7 \%$ as Black or African American, 5.6\% as Hispanic or Latino, 5.2\% as Asian, and $1.4 \%$ as American Indian or Alaskan Native. ${ }^{14}$

\section{Materials and Methods Study Design and Participants}

Between December 2019 and February 2020, the authors conducted a cross-sectional electronic survey of all first, second, third, and fourth-year medical students (abbreviated as MS1, MS2, MS3, and MS4, respectively) at both University of Minnesota Medical School campuses (Minneapolis and Duluth). The two campuses vary by mission, class size, geographic location, and preclinical curricula. During the preclinical years, Duluth and Minneapolis medical students do not share any courses or interact in the academic environment. First- and secondyear students were asked to respond to survey items with respect to their current experience in preclinical curricula, whereas third- and fourth-year students were asked to respond considering past preclinical curricular experiences.

\section{Preclinical Curriculum Survey Instrument}

The first two items asked respondents to estimate the total number of hours per week that they felt medical school consumes, and the number of hours they spend learning $\mathrm{SDH}$. Respondents then were asked to rate the level of focus on SDH in the preclinical curriculum ("Not enough", "Appropriate", or "Too much"), and where they would place their understanding of SDH relative to their peers ("Less than", "About the same", or "More than"). Additionally, the survey included five demographic items: age, gender, race, year of study, and medical school campus (See Appendix for the Complete Survey).

We developed the 9-item electronic survey with expert guidance from the institution's Manager of Evaluation and Analytics. A final version of each survey was reviewed and approved by all authors and the Manager of Evaluation and Analytics. We validated the survey post 
hoc using cognitive interviews conducted with five medical students who were not included in the study. Cognitive interviews were structured as "concurrent think alouds" in which respondents described their own interpretation of each item. ${ }^{15}$ All five medical students interpreted all questions as intended by the survey design. Statistical measures of internal consistency (eg, Cronbach's alpha) were not calculated, as they are generally inappropriate in cases, like ours, where questions are not designed to measure the same latent variable.

We administered the survey electronically using the web-based survey platform Qualtrics (Provo, Utah). The link to the web-based survey and a short description of its purpose was emailed to students using institutional listservs. Reminder emails to complete the survey were sent three times over a ten-day period to all students. To encourage participation while maintaining anonymity, we asked those who completed the survey to attest completion through a separate form from which we randomly selected a total of six participants for a $\$ 50$ cash prize. The University of Minnesota Medical School Institutional Review Board (IRB) deemed this study "not human research" (IRB ID\# STUDY00008416), therefore informed consent was not necessary.

\section{Data Analysis}

We report descriptive summary statistics as frequencies with percentages. Variations in gender and race definitions between our survey and medical school population data were reconciled to allow for comparison. We compared the gender, race, year in training, and campus of respondents with those of the entire University of Minnesota Medical School student population. Differences in distributions were assessed using chi-squared goodness-of-fit tests and one-proportion tests as appropriate for each.

We used multiple logistic regression analysis to evaluate the relative odds of rating the amount of preclinical focus on SDH as "Not enough" for each gender and racial identity. The group with the highest count was selected as the reference group for each variable. In our model we also adjusted for year of training and campus to account for 1) our expectation that students' understanding of SDH changes as they advance through their training, and 2) the potential that curricular differences between campuses may impact students' perspectives on SDH in the curriculum. We excluded responses with missing data from the regression analysis. All $p$-values in our analyses were twosided with an alpha level of 0.05 . We performed our statistical analyses in $\mathrm{R}$ version 4.0.2 ${ }^{16}$ using the tidyverse packages ${ }^{17}$ for data management and graphics and the $\mathrm{glm}$ () function for multiple logistic regression.

\section{Results}

Of 1010 first-, second-, third-, and fourth-year medical students invited to participate, $515(51.0 \%)$ responded and their characteristics are shown in Table 1. The distribution of respondents with respect to campus was similar to that of the medical school student body $(p=0.49)$. Response rates varied with respect to gender, race, and year of training $(p<0.001)$, with the largest difference being an $8.6 \%$ greater-than-expected response rate among women.

Figure 1 illustrates the total number of hours per week students reported spending on medical school relative to the number of hours per week they reported spending on SDH. The vast majority of medical students $(93.2 \%$; 480/ 515) reported that they spend 40 or more hours per week on medical school. Among these students, most (84.4\%; 405/480) said they spend 0 to 2 hours weekly on SDH.

As depicted in Table 2, 62.1\% of students felt the level of focus on SDH is "Not enough", 35.7\% felt it is "Appropriate", and only $2.1 \%$ felt it is "Too much". Responses varied significantly with respect to gender identity and race. Nearly all students who identify as Black or African American (89.7\%) rated the level of curricular focus on SDH as "Not enough", in contrast to $58.3 \%$ of white students. In a multiple logistic model that adjusted for gender, campus, and year in school, students who identified as Black or African American were 4.19-times (aOR 4.19; 95\% CI, 1.37-18.38) as likely as students who identified as white (reference) to rate the level of preclinical focus on SDH as "Not enough". In a secondary analysis of white and "non-white" students (defined as all other races combined), "non-white" students were 1.75-times (aOR 1.75; 95\% CI, 1.09-2.85) as likely as white (reference) to choose "Not enough". Over two-thirds of women (68.3\%) but only about half of men (51.3\%) rated the level of curricular focus on SDH as "Not enough". Adjusting for race, campus, and year in school, women were 2.3-times (aOR 2.30; 95\% CI $1.52-3.49)$ as likely as men to select "Not enough".

\section{Discussion}

In this cross-sectional electronic survey study of 515 medical students at both campuses of a large public medical school, we found that the majority of medical students were spending 40 or more hours per week on medical school, with only $0-2$ of those hours allocated to learning 
Table I Demographic Summary of Survey Respondents and the University of Minnesota Medical School Student Body

\begin{tabular}{|c|c|c|c|c|c|}
\hline & Respondents $(N=515)$ & $\%$ & $\begin{array}{l}\text { Student Body } \\
(N=10 \mid 0)\end{array}$ & $\%$ & $\begin{array}{l}\text { p-value for Test of No } \\
\text { Difference }\end{array}$ \\
\hline Gender Identity* & 509 & & 1010 & & $<0.001$ \\
\hline Woman & 319 & 62.7 & 546 & 54.1 & \\
\hline Man & 187 & 36.7 & 464 & 45.9 & \\
\hline Trans Man & I & 0.2 & & & \\
\hline Trans Woman & 0 & 0 & & & \\
\hline $\begin{array}{l}\text { Non-binary or Gender Non- } \\
\text { conforming }\end{array}$ & 1 & 0.2 & & & \\
\hline Other Gender Identity & 1 & 0.2 & & & \\
\hline Racial Identity & 497 & & 898 & & $<0.001$ \\
\hline White & 369 & 74.2 & 634 & 70.6 & \\
\hline Asian & 48 & 9.7 & 115 & 12.8 & \\
\hline Black or African American & 29 & 5.8 & 62 & 6.9 & \\
\hline Hispanic, Latino, or Spanish Origin & 20 & 4.0 & 32 & 3.6 & \\
\hline American Indian or Alaska Native & 12 & 2.4 & 43 & 4.8 & \\
\hline $\begin{array}{l}\text { Native Hawaiian or Other Pacific } \\
\text { Islander }\end{array}$ & I & 0.2 & 2 & 0.2 & \\
\hline Other Racial Identity ${ }^{\dagger}$ & 18 & 3.6 & 10 & I.I & \\
\hline Year in school & 515 & & 972 & & $<0.001$ \\
\hline MSI & $14 \mid$ & 27.4 & 255 & 26.2 & \\
\hline MS2 & 168 & 32.6 & 254 & 26.1 & \\
\hline MS3 & 104 & 20.2 & 267 & 27.5 & \\
\hline MS4 & 102 & 19.8 & 196 & 20.2 & \\
\hline Campus & 515 & & 1010 & & 0.49 \\
\hline Minneapolis & 375 & 72.8 & 750 & 74.3 & \\
\hline Duluth & $|4|$ & 27.2 & 260 & 25.7 & \\
\hline
\end{tabular}

Notes: *Gender was reported as "Male" or "Female" by the university. These titles were used as surrogates for "Man" and "Woman", respectively, to test for differences in percentage of women between survey respondents and the medical school student population. 'Defined as "Not specified" in data provided by the University of Minnesota.

about SDH. We also found women and Black students were more likely than men and white students, respectively, to desire more SDH content in medical school curricula.

While the idea of increasing the amount of time that medical students are spending learning about SDH is not novel, ${ }^{6,7,18,19}$ this study provides the first data, to our knowledge, on the amount of time students are allocating to SDH in practice. The finding that women and Black students desired more SDH content is unsurprising, but worthy of examining in the context of existing literature.

\section{Explaining the Paradox - Why Would so Little Time Feel "Appropriate" or "Too Much"?}

Social and structural forces contribute significantly to health outcomes and help explain health disparities, yet our study suggests that future healthcare providers are devoting a small fraction of their time (0-2 hours out of $40+$ hours) learning about these forces during the first two years of medical school. Moreover, the proportion of time spent on SDH likely overestimates the curricular focus on these topics, as responses included both curricular and self-directed learning. This discrepancy is particularly striking in light of the recent expert consensus that $29 \%$ of time ought to be dedicated to SDH during the preclinical years of medical school. ${ }^{4}$

When asked about the current level of focus allocated to $\mathrm{SDH}$ in the preclinical curricula, only $2.1 \%$ (11 students) rated the focus level as "Too much", while 35.7\% rated it as "Appropriate" and 62.1\% rated it as "Not enough". Considering most students are spending only 0-2 hours per week on SDH, we ought to examine why $37.9 \%$ selected "Appropriate" or "Too much". We offer two possible explanations. 


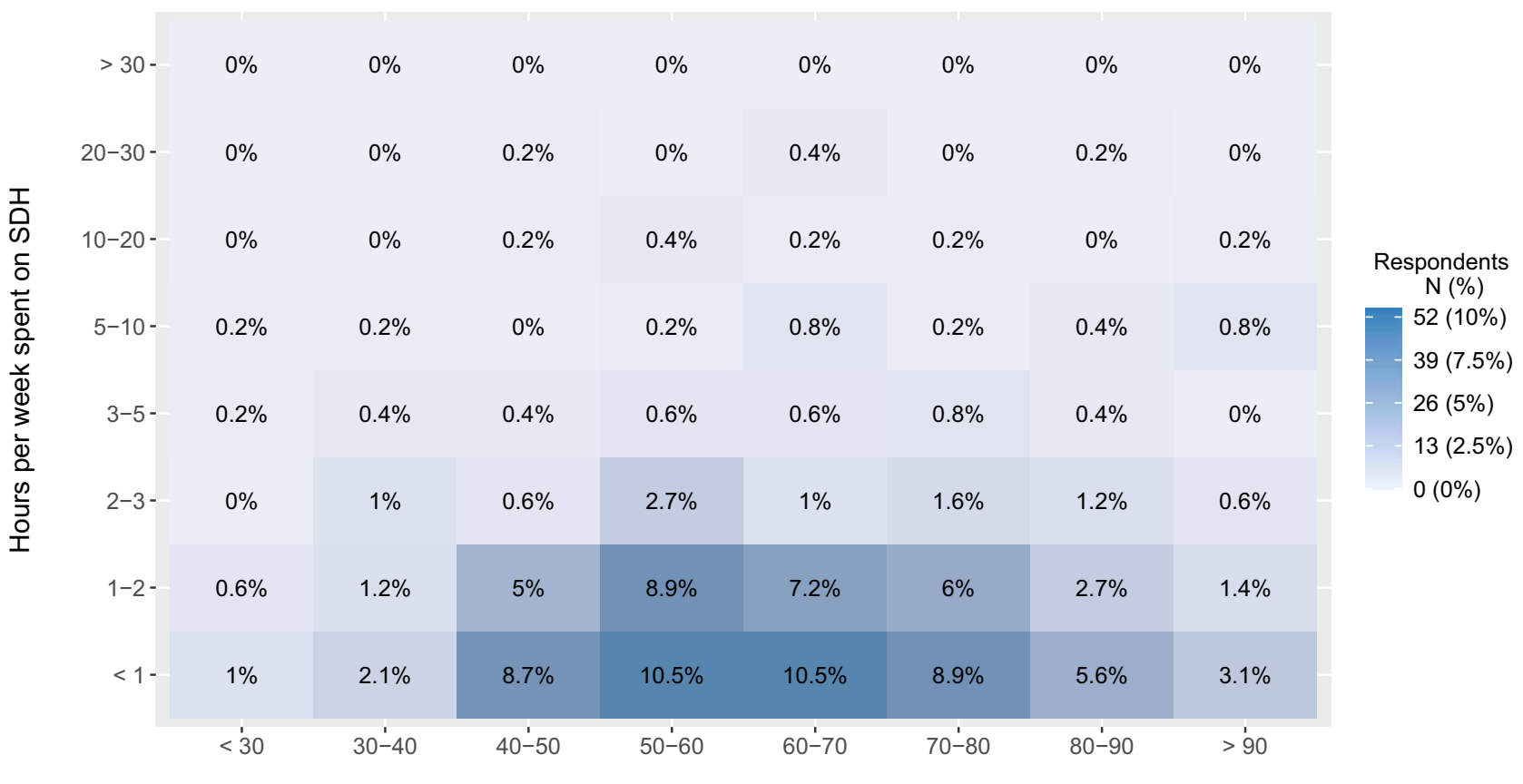

Total hours per week spent on medical school

Figure I Heat map of time spent per week (hours) on medical school and time spent per week (hours) on SDH. Each cell displays the percentage of respondents (of 5 I 5 total respondents) who selected the corresponding combination of weekly hours spent on SDH and medical school. There were no missing data for either of these variables.

The first is that medical students are taught that objectivity - an attribute ascribed with high value in medicine must be rooted in the materiality of the body. ${ }^{20}$ Medical training has long accelerated the centering of biology as the purest, most unbiased form of knowledge needed to successfully diagnose and treat disease. ${ }^{21}$ In parallel, medicine actively works to dismiss the social as peripheral. This dismissal occurs in part because the social is seen to obscure the pure presentation and identification of disease. Acknowledging the social also threatens the authority and power that medicine generates for itself by locating pathology in the body. The powerful influence of these narratives in medical training may drive the feeling that very little content on SDH is "Appropriate" or "Too much".

Secondly, medical students' explicit or implicit beliefs may be substantiated by the relative weight assigned to traditional biomedicine (ie histology, genetics, biochemistry) in pivotal standardized examinations such as the United States Medical Licensing Examination (USMLE) Step 1 exam. Medical students, fully aware of the exam's content distribution, may view "non-traditional" content - such as topics addressing SDH - as time and energy lost in the zero-sum game that is preparing for and performing on Step 1. Indeed, an intense focus on Step 1 test scores has been shown to stifle medical curriculum development, as students prioritize memorizing test material over seeking other knowledge. ${ }^{22}$

\section{Lived Experiences of Women and Black Students}

White students and men disproportionately comprised the $37.9 \%$ group who rated the level of preclinical curricular focus on SDH as "Appropriate" or "Too much", while Black students and women were significantly more likely to rate the level of focus on SDH as "Not enough." Lived experiences within and outside the learning environment may shape our critical consciousness and inform our educational desires as well as our interpretation of the quantity, content, and quality of SDH education in medical school. Women and BIPOC-identifying students may arrive with a deeper critical consciousness of the social forces that impact their lives and health.

The development of critical consciousness - an awakening to the oppressive forces of the world and one's relation to those forces - involves learning about the systems and structures that have created and maintained inequities (critical analysis), developing a sense of power or capability (sense of agency), and committing to acting against oppressive conditions (critical action). ${ }^{23,24}$ Applying this lens to our data, we propose that women and BIPOC students - specifically those who 
Table 2 Summary of How Respondents Felt About the Level of Preclinical Curricular Focus on Social Determinants of Health

\begin{tabular}{|c|c|c|c|c|c|}
\hline & \multicolumn{3}{|c|}{ Level of Curricular Focus on SDH } & \multirow[b]{2}{*}{$\begin{array}{l}\text { aOR }(95 \% \mathrm{Cl}) \text { for } \\
\text { answering "Not enough" }\end{array}$} & \multirow[b]{2}{*}{$p$-value } \\
\hline & “Not enough" & "Appropriate" & “Too much" & & \\
\hline All & $320(62.1 \%)$ & $184(35.7 \%)$ & II (2.1\%) & & \\
\hline \multicolumn{6}{|l|}{ Gender Identity } \\
\hline Woman & $218(68.3 \%)$ & 97 (30.4\%) & $4(1.3 \%)$ & [Reference] & \\
\hline Man & $96(51.3 \%)$ & $85(45.5 \%)$ & $6(3.2 \%)$ & $0.43(0.29-0.66)$ & $<0.001$ \\
\hline Trans Man & I (100\%) & $0(0 \%)$ & $0(0 \%)$ & $*$ & $*$ \\
\hline Non-binary or Gender & I (100\%) & $0(0 \%)$ & $0(0 \%)$ & $*$ & $*$ \\
\hline Non-conforming & & & & & \\
\hline Other Gender Identity & $0(0 \%)$ & I (100\%) & $0(0 \%)$ & $*$ & $*$ \\
\hline \multicolumn{6}{|l|}{ Racial Identity } \\
\hline White & $215(58.3 \%)$ & $147(39.8 \%)$ & 7 (1.9\%) & [Reference] & \\
\hline Asian & $32(66.7 \%)$ & $16(33.3 \%)$ & $0(0 \%)$ & $1.07(0.55-2.14)$ & 0.84 \\
\hline $\begin{array}{l}\text { Black or African } \\
\text { American }\end{array}$ & $26(89.7)$ & $2(6.9 \%)$ & I (3.4\%) & $4.19(1.37-18.38)$ & 0.03 \\
\hline $\begin{array}{l}\text { Hispanic, Latino, or } \\
\text { Spanish Origin }\end{array}$ & 15 (75\%) & $5(25 \%)$ & $0(0 \%)$ & I.68 (0.6I-5.42) & 0.34 \\
\hline $\begin{array}{l}\text { American Indian or } \\
\text { Alaska Native }\end{array}$ & 7 (58.3\%) & 5 (4I.7\%) & $0(0 \%)$ & $2.2(0.64-8.18)$ & 0.22 \\
\hline $\begin{array}{l}\text { Native Hawaiian or } \\
\text { Other Pacific Islander }\end{array}$ & $0(0 \%)$ & I (100\%) & $0(0 \%)$ & $*$ & $*$ \\
\hline Other Racial Identity & 15 (83.3\%) & $3(16.7 \%)$ & $0(0 \%)$ & $3.11(0.94-14.27)$ & 0.09 \\
\hline
\end{tabular}

Notes: Adjusted odds ratios (aORs) indicate the adjusted odds of selecting "Not enough". Reference groups were the groups with the highest number of responses. Gender Identity aOR adjusts for race, campus, and year in school. Racial identity aOR adjusts for gender, campus, and year in school. *Too few respondents to calculate the odds ratios for these categories.

identified as Black or African American at our institution have developed a sense of agency that has resulted in a heightened attention around SDH content. In fact, previous work suggests that critical consciousness of oppressive social forces can replace feelings of isolation and self-blame with a sense of engagement in a broader collective effort toward social justice. $^{25,26}$

The differential lived experiences of women and BIPOC students can in turn establish expectations for care. Women training to become physicians increasingly believe in the need to address psychosocial factors, and demonstrate interest in receiving more training to address them. $^{27}$ These socially prescribed, gendered expectations of women are reaffirmed throughout medical training and collectively create "hidden rules" for providing care. Women not only disproportionately see more psychosocially complex patients than their male colleagues, but are also expected to do so by both patients and colleagues. ${ }^{28,29}$ A similar set of "hidden rules" may exist for BIPOCidentifying physicians as it pertains to caring for racial and ethnically minoritized patients and working in underserved communities. These expectations may be especially salient for students with intersecting marginalized identities, such as women of color. ${ }^{30}$ Like many gendered and racialized societal expectations, these "rules" are learned, internalized, and reinforced many times over before medical students become full practicing physicians, and may thus drive greater affinity toward SDH material.

\section{Protecting Narratives and Structures}

We further propose that people more likely to benefit from the current structures, policies, and practices of social, political, and economic systems - particularly men and white people - may have less of a desire to study SDH in order to consciously or subconsciously protect entrenched narratives they hold about the value of hard work and intelligence. A belief in the correlation between hard work and intelligence (the "best and the brightest") with success in medical school is heavily embedded in the psyches of medical students, likely to an even greater extent in those who experience societally conferred 
privilege. ${ }^{31}$ Engagement with a SDH framework counters these narratives by demonstrating that one's success, opportunities, and health are much more impacted by social forces than one's personal choices, behaviors, or inherent capabilities. Thus, it is possible that evading SDH content may be a psychological strategy to avoid the cognitive dissonance associated with acknowledging that one's place in life has much more to do with power and privilege than industriousness and natural talent. ${ }^{32}$

\section{Next Steps and Recommendations}

First and foremost, we would like to see these findings reproduced at a geographically diverse sample of medical schools. In parallel, future qualitative work should explore why such a large percentage of students devalue SDH education. Hypotheses this future work may leverage include those discussed in this paper: the weight given to standardized exams, differential lived experiences and critical consciousness, protection of narratives, social expectations and "hidden rules".

Conducting a similar survey, in the midst of the COVID-19 pandemic and social unrest following the brutal police killing of George Floyd, would also shed light on how societal events shape the curricular perceptions of medical students. Our unstable social context offers a rare moment for medicine to either support the emergence of new health professional perceptions and practices, or to seek refuge in tradition and convention.

With the recent announcement that the USMLE Step 1 will be moving to pass/fail as early as 2022, medical educators have an opportunity to reassess preclinical curricular priorities - including offering a more robust SDH curriculum. In doing so, we recommend that medical schools not only focus on making sure they are incorporating SDH content, but that they also align the pedagogy to the unique challenges of SDH education. This may include drawing from a variety of creative and reflective teaching methods in the literature to create transformative learning opportunities while engaging all students in SDH content regardless of their starting place. ${ }^{33-36}$

Finally, preclinical curricular reform should elevate the voices of both students and faculty identifying as women and BIPOC, as these individuals are more likely to have felt the effects of social forces on health and well-being.

\section{Limitations}

Several factors limit the generalizability of our findings. The first is sampling bias, given we only surveyed two campuses of a single, public medical school. Although the Minneapolis and Duluth campuses vary considerably by mission, class size, and preclinical curricula, they do share a parent institution, which may hold other elements constant. The gender and race differences we found may be influenced by the culture and geography of these medical schools - Minnesota being a predominantly white state. ${ }^{14}$ Secondly, we did observe small demographic differences between responders and non-responders, which raises concern for non-response bias. Third, although our survey questions were assessed post-hoc for validity using cognitive interviews, no formal psychometric evaluation of the instrument was conducted. Future work should build on these findings using validated instruments and larger, multiinstitutional and geographically diverse samples. Finally, one reviewer noted there was no a priori expected effect size and corresponding power calculation. We intend this study as a proof of concept that establishes motivation for further, more rigorous studies; however, we acknowledge the need to include such measures in future work.

\section{Conclusion}

Our study serves as a starting point in understanding how medical students perceive SDH education. In practice, medical students are spending considerably less time learning $\mathrm{SDH}$ than is advised by consensus of expert educators and administrators, and most medical students want more SDH content in the curriculum. Specifically, women and racial minority students disproportionately rated the curricular focus on SDH as "Not enough". As our study preceded both the start of the COVID-19 pandemic and ongoing mass racial-injustice protests across the United States, future work ought to consider how current events have impacted and shaped medical student beliefs about the inclusion of SDH in curricula.

\section{Acknowledgements}

The authors want to thank Jackie Gauer from the University of Minnesota Office of Assessment and Evaluation for her help developing the survey instrument.

\section{Disclosure}

The authors report no conflicts of interest in this work. 


\section{References}

1. Krieger N, Van Wye G, Huynh M, et al. Structural racism, historical redlining, and risk of preterm birth in New York City, 2013-2017. Am $J$ Public Health. 2020;110(7):1046-1053. doi:10.2105/ AJPH.2020.305656

2. Felitti VJ, Anda RF, Nordenberg D, et al. Relationship of childhood abuse and household dysfunction to many of the leading causes of death in adults: the Adverse Childhood Experiences (ACE) Study. Am J Prev Med. 1998;14(4):245-258. doi:10.1016/S0749-3797(98) 00017-8

3. Waitzkin H. The Politics of Medical Encounters: How Patients and Doctors Deal with Social Problems. 1991. doi:10.5860/choice.293341

4. Mangold KA, Bartell TR, Doobay-Persaud AA, Adler MD, Sheehan KM. Expert consensus on inclusion of the social determinants of health in undergraduate medical education curricula. Acad Med. 2019;94(9):1355-1360. doi:10.1097/ACM.0000000000002593

5. Chaiyachati KH, Grande DT, Aysola J. Health systems tackling social determinants of health: promises, pitfalls, and opportunities of current policies. Am J Manag Care. 2016;22(11):e393-e394.

6. Byhoff E, Kangovi S, Berkowitz SA, et al. A society of general internal medicine position statement on the internists' role in social determinants of health. J Gen Intern Med. 2020;35(9):2721-2727. doi:10.1007/s11606-020-05934-8

7. Daniel H, Bornstein SS, Kane GC. Addressing social determinants to improve patient care and promote health equity: an American college of physicians position paper. Ann Intern Med. 2018;168(8):577-578. doi:10.7326/M17-2441

8. Doobay-Persaud A, Adler MD, Bartell TR, et al. Teaching the social determinants of health in undergraduate medical education: a scoping review. J Gen Intern Med. 2019;34(5):720-730. doi:10.1007/s11606019-04876-0

9. Standards, publications, \& notification forms. LCME. Available from: https://lcme.org/publications/\#Standards. Accessed August 12, 2020.

10. Social determinants for health by academic level. AAMC. Available from: https://www.aamc.org/data-reports/curriculum-reports/interac tive-data/social-determinants-health-academic-level. Accessed September 22, 2020.

11. Take two aspirin and call me by my pronouns. WSJ. Available from: https:/www.wsj.com/articles/take-two-aspirin-and-call-me-by-mypronouns-11568325291. Accessed July 7, 2020.

12. Hill KA, Samuels EA, Gross CP, et al. Assessment of the prevalence of medical student mistreatment by sex, race/ ethnicity,and sexual orientation. JAMA Intern Med. 2020;180(5):653. doi:10.1001/ jamainternmed.2020.0030

13. Shapiro T, Meschede T, Osoro S. The Roots of the Widening Racial Wealth Gap: Explaining the Black-White Economic Divide. Institute on Assets and Social Policy; 2013:8.

14. U.S. census bureau quickFacts: Minnesota. Available from: https:// www.census.gov/quickfacts/MN. Accessed September 22, 2020.

15. Drennan J. Cognitive interviewing: verbal data in the design and pretesting of questionnaires. $J$ Adv Nurs. 2003;42(1):57-63. doi:10.1046/j.1365-2648.2003.02579.x

16. R Core Team. R: a language and environment for statistical computing. $\mathrm{R}$ foundation for statistical computing; 2020. Available from: https://www.R-project.org. Accessed May 11, 2021.
17. Wickham H, Averick M, Bryan J, et al. Welcome to the Tidyverse. J Open Source Softw. 2019;4(43):1686. doi:10.21105/joss.01686

18. National Academies of Sciences E. Integrating Social Care into the Delivery of Health Care: Moving Upstream to Improve the Nation's Health. 2019. doi:10.17226/25467

19. Karra L, Johnson M, Piggott C. Defunding of diversity and inclusion programs in undergraduate and graduate medical education. PRiMER. 2020;4. doi:10.22454/PRiMER.2020.971896

20. Good BJ. Medicine, Rationality, and Experience: An Anthropological Perspective. 1993.

21. Foucault M. The Birth of the Clinic: An Archaeology of Medical Perception. 1975.

22. Prober CG. Grading changes for USMLE step 1 - a golden opportunity to recalibrate medical education priorities. $N$ Engl J Med. 2020;382(25):2385-2387. doi:10.1056/NEJMp2003880

23. El-Amin A, Seider S, Graves D, et al. Critical consciousness: a key to student achievement. Phi Delta Kappan. 2017;98(5):18-23. doi: $10.1177 / 0031721717690360$

24. Freire P, Macedo D. Pedagogy of the Oppressed, 30th Anniversary Edition. 30th ed. Continuum; 2000.

25. Diemer MA, Rapa LJ, Park CJ, Perry JC. Development and validation of the critical consciousness scale. Youth Soc. 2017;49 (4):461-483. doi:10.1177/0044118X14538289

26. Ginwright SA. Black Youth Rising: Activism and Radical Healing in Urban America. Illustrated ed. Teachers College Press; 2009.

27. Astin JA, Sierpina VS, Forys K, Clarridge B. Integration of the biopsychosocial model: perspectives of medical students and residents. Acad Med. 2008;83(1):20-27. doi:10.1097/ ACM.0b013e $31815 \mathrm{c} 61 \mathrm{~b} 0$

28. McMurray JE, Linzer M, Konrad TR, Douglas J, Shugerman R, Nelson K. The work lives of women physicians. J Gen Intern Med. 2000;15(6):372-380. doi:10.1111/j.1525-1497.2000.im9908009.x

29. Linzer M, Harwood E. Gendered expectations: do they contribute to high burnout among female physicians? J Gen Intern Med. 2018;33 (6):963-965. doi:10.1007/s11606-018-4330-0

30. Raj A, Kumra T, Darmstadt GL, Freund KM. Achieving gender and social equality: more than gender parity is needed. Acad Med. 2019;94(11):1658-1664. doi:10.1097/ACM.0000000000002877

31. Razack S, Risør T, Hodges B, Steinert Y. Beyond the cultural myth of medical meritocracy. Med Edu. 2020;54(1):46-53. doi:10.1111/ medu. 13871

32. White fragility: why it's so hard for white people to talk about racism; 2018. Available from: https://bookshop.org/books/whitefragility-why-it-s-so-hard-for-white-people-to-talk-about-racism 19780807047415. Accessed August 13, 2020.

33. Van Schalkwyk SC, Hafler J, Brewer TF, et al. Transformative learning as pedagogy for the health professions: a scoping review. Med Educ. 2019;53(6):547-558. doi:10.1111/medu.13804

34. Sabato E, Owens J, Mauro AM, Findley P, Lamba S, Fenesy K. Integrating social determinants of health into dental curricula: an interprofessional approach. $J$ Dent Educ. 2018;82(3):237-245. doi:10.21815/JDE.018.022

35. Thornton M, Persaud S, Wilson M, Gross D. Preparing today's nurses: social determinants of health and nursing education. Online J Issues Nurs. 2018;23(3). doi:10.3912/OJIN.Vol23No03Man02

36. Joshua N, Holmes Seth M, Knight Kelly R, et al. Structural competency: curriculum for medical students, residents, and interprofessional teams on the structural factors that produce health disparities. MedEdPORTAL. 2020;16. doi:10.15766/mep_2374-8265.10888 


\section{Publish your work in this journal}

Advances in Medical Education and Practice is an international, peerreviewed, open access journal that aims to present and publish research on Medical Education covering medical, dental, nursing and allied health care professional education. The journal covers undergraduate education, postgraduate training and continuing medical education including emerging trends and innovative models linking education, research, and health care services. The manuscript management system is completely online and includes a very quick and fair peer-review system. Visit http://www.dovepress.com/testimonials.php to read real quotes from published authors. 